\title{
Programa de Residência Pedagógica: perspectivas iniciais e desafios na implementação
}

\section{Residência pedagógica Program: initial perspectives and implementation challenges}

\author{
Renata Godinho Soares (renatasoares1807@gmail.com)
}

Universidade Federal do Pampa (UNIPAMPA)

\author{
Verônica de Carvalho Vargas (veronicadecarvalhovargas@gmail.com) \\ Universidade Federal do Pampa (UNIPAMPA)
}

Vinícius Gonçalves Mariano (viniciusmarianno.unipampa@gmail.com)

Universidade Federal do Pampa (UNIPAMPA)

Raquel Ruppenthal (raquelruppenthal@unipampa.edu.br)

Universidade Federal do Pampa (UNIPAMPA)

\begin{abstract}
Resumo:
Este estudo tem como objetivo analisar as perspectivas iniciais bem como analisar e descrever os desafios após a implementação do Programa de Residência Pedagógica na Universidade Federal do Pampa - Uruguaiana/RS. Foram sujeitos do estudo, 29 residentes e preceptores atuantes em dois núcleos do programa, bem como as duas docentes orientadoras destes. Para a coleta de dados dos residentes e preceptores, utilizou-se de um questionário disponibilizado via e-mail, e para as docentes orientadoras, organizou-se uma entrevista semiestruturada. Ambos instrumentos continham questões relacionadas as perspectivas iniciais, os desafios do programa e se este os auxiliou no processo de formação acadêmico-profissional. Para a análise do material, realizou-se Análise de Conteúdo. Dentre os achados, foi possível perceber que o programa proporcionou aos participantes um elo bastante forte entre a teoria e a prática, como também possibilitou aos residentes conhecer e intervir na realidade escolar além de proporcionar aos preceptores o retorno ao meio acadêmico. Por fim, através deste, percebeu-se ao longo da análise das falas que a formação acadêmicoprofissional foi uma constante, possibilitando vivências tanto no campo da escola como na universidade a qual fazem parte os núcleos investigados.
\end{abstract}

Palavras-chave: formação acadêmico-profissional; universidade; educação básica.

\section{Abstract:}

This study aims to analyze the initial perspectives as well as analyze and describe the challenges after the implementation of the Residência Pedagógica Program at the Universidade Federal do Pampa - Uruguaiana/RS. The study subjects were 29 residents and preceptors working in two centers of the program, as well as their two guiding teachers. To collect data from residents and preceptors, was used a questionnaire available via e-mail, and for the guiding teachers, a semi-structured interview was organized. Both instruments contained questions related to the initial perspectives, the challenges of the program and whether it helped them in the process of academicprofessional formation. For the analysis of the material, was performed Content 
Vol. 3, n. 1. Jan./Abr. 2020 - ISSN 2595-4520

Analysis. Among the findings, it was possible to notice that the program provided participants with a very strong link between theory and practice, as well as allowing residents to know and intervene in the school reality and provide preceptors with a return to the academic environment. Finally, through this, it was realized throughout the analysis of the statements that the academic-professional formation was a constant, enabling experiences both in the field of the school and in the university to which the nuclei investigated are part.

Keywords: academic-professional education; university; basic education.

\section{INTRODUÇÃO}

Este trabalho, relacionado à formação de professores, posiciona-se na contramão da compreensão de formação de professores(as) que separa este processo em "formação inicial" e "formação continuada". Por outro lado, o conceito apresentado pelo professor Júlio Emílio Diniz-Pereira "formação acadêmico-profissional" nos parece mais apropriado para o tema deste trabalho. A formação acadêmico-profissional busca promover práticas educativas realizadas entre professores(as) experientes e iniciantes, em parcerias universidade-escola, para atingir objetivos comuns, na (re)construção do conhecimento e em proposições transformadoras da realidade (MELLO, FREITAS; 2019).

É sabido que a formação de professores se constrói através de um trabalho de reflexão crítica sobre as práticas e de (re)construção permanente de uma identidade pessoal. Por isso é tão importante investir na pessoa e dar estatuto ao saber da experiência (NÓVOA, 1995). Tornar-se professor é transformar uma predisposição numa disposição pessoal. Precisamos de espaços e de tempos que permitam um trabalho de autoconhecimento e de autoconstrução. Precisamos de um acompanhamento, de uma reflexão sobre a profissão (NÓVOA, 2017).

Nesse sentido, Diniz-Pereira (2008) defende a necessidade de que a formação de professores seja assumida como acadêmico-profissional, ao problematizar o termo 'formação inicial' e 'Formação Continuada' “[...] tão vastamente difundido na literatura da área da educação e adotado acriticamente por meio da importação de resultados de pesquisas realizadas em contextos educacionais bastante diferentes daqueles encontrados em nosso país" (DINIZ-PEREIRA, 2008, p. 253).

Segundo o autor, são princípios necessários à formação de professores: 
Vol. 3, n. 1. Jan./Abr. 2020 - ISSN 2595-4520

[...] conceber o ensino como uma atividade profissional apoiada em um sólido repertório de conhecimentos, entender a prática profissional como um lugar de formação e de produção de saberes pelos práticos e estabelecer ligação entre as instituições universitárias de formação e as escolas da Educação Básica” (DINIZ-PEREIRA, 2011, p. 213).

A Lei de Diretrizes e Bases da Educação Nacional (BRASIL, Lei 9.394/1996), sinalizava que "a União, o Distrito Federal, os Estados e os Municípios, em regime de colaboração, deverão promover a formação inicial, a continuada e a capacitação dos profissionais de magistério" (BRASIL, 1996). Em 2018, a Coordenação de Aperfeiçoamento de Pessoal de Nível Superior - CAPES, tornou público o edital $\mathrm{n}^{\circ} 06$ em 2018, com o objetivo de realizar uma chamada pública para selecionar Instituições de Ensino Superior interessadas em apresentar propostas para a implementação do Programa de Residência Pedagógica (PRP).

Um dos principais objetivos do PRP é articular teoria e prática, aproximando a universidade do campo prático, fortalecendo o vínculo com as redes públicas de educação básica, aperfeiçoando a formação de discentes de cursos de licenciaturas de Instituições de Ensino Superior. Vale ressaltar que um dos objetivos do PRP é “promover a adequação dos currículos e propostas pedagógicas dos cursos de formação inicial de professores da educação básica às orientações da Base Nacional Comum Curricular (BNCC)" (Edital nº 06 da CAPES/2018).

O PRP está organizado em torno de três agentes principais: os residentes, que são os acadêmicos de licenciatura; os preceptores, que são professores da Educação Básica que acompanham diretamente os residentes; e os docentes orientadores, que são docentes do Ensino Superior da IES que acolhe o programa.

Na Universidade Federal do Pampa (UNIPAMPA), o programa teve início no ano de 2018, articulando as propostas em seis subprojetos, organizados em 09 núcleos que são desenvolvidos em sete municípios do estado do Rio Grande do Sul: Bagé, Dom Pedrito, Uruguaiana, São Borja, Caçapava do Sul e São Gabriel, Candiota e Aceguá. Dentre estes, a pesquisa em questão terá como foco os dois núcleos de Uruguaiana.

O PRP na UNIPAMPA-Campus Uruguaiana/RS, objeto deste estudo conta com 07 preceptores, 45 residentes e 02 docentes orientadoras, respectivamente, professores de escola pública e acadêmicos da licenciatura de ambos os cursos das áreas de Ciências da Natureza e Educação Física. Visando compreender como se deu o processo de implementação do PRP nesses núcleos, este estudo tem como objetivo analisar as 
Vol. 3, n. 1. Jan./Abr. 2020 - ISSN 2595-4520 perspectivas iniciais bem como analisar e descrever os desafios após a implementação do Programa de Residência Pedagógica na Universidade Federal do Pampa Uruguaiana/RS.

\section{METODOLOGIA}

Este estudo de cunho qualitativo caracterizou-se como uma pesquisa de campo, com caráter exploratório e descritivo a fim de familiarizar-se com um assunto ainda pouco conhecido, pouco explorado (GIL, 2010). Para Minayo (2002), a pesquisa qualitativa:

Trabalha com o universo de significados, motivos, inspirações, crenças, valores e atitudes, o que correspondem a um espaço mais profundo das relações, dos processos e dos fenômenos que não podem ser reduzidos à operacionalização de variáveis" (MINAYO, 2002, p.21-22).

O público participante deste estudo foram os residentes, preceptores e docentes orientadoras do PRP dos núcleos de Ciências da Natureza e Educação Física. No quadro 1, fica especificado a população total correspondente a cada núcleo.

Quadro 1: Caracterização dos participantes de acordo com núcleo participante

\begin{tabular}{|l|l|}
\hline \multicolumn{2}{|c|}{ Subprojeto - UNIPAMPA Campus Uruguaiana/RS } \\
\hline \multicolumn{1}{|c|}{ Núcleo Ciências da Natureza } & Núcleo Educação Física \\
\hline Residentes $=18$ & Residentes $=22$ \\
\hline Preceptores $=04$ & Preceptores $=03$ \\
\hline Docentes Orientadores $=01$ & Docentes Orientadores $=01$ \\
\hline
\end{tabular}

Fonte: das autoras (2019).

Inicialmente, realizou-se o contato com as docentes orientadoras com intuito de explicar o objetivo da pesquisa e que, em caso de concordância na participação, as mesmas deveriam manifestar consentimento, como também responder a uma entrevista semiestruturada. Nesse momento, também foram informadas que, posteriormente, um questionário online seria encaminhado via endereço eletrônico a seu grupo de residentes e preceptores. Cada participante foi nomeado para fins de análise, com a letra referente a função no PRP seguida de numeração. Como por exemplo: DO1, DO2 (Docente orientador); P1, P2, P3 (Preceptor); R1, R2, R3 (Residente). 
Os instrumentos utilizados nesta pesquisa, foram elaborados pelos pesquisadores, sendo eles, um roteiro de entrevista semiestruturada e um questionário online com questões abertas. Ambos foram validados previamente a sua aplicação. Após o consentimento dos docentes orientadores, agendou-se horários para as entrevistas. As questões: "Qual sua percepção inicial sobre o Programa Residência Pedagógica?"; "Quais suas expectativas futuras para com o programa?"; "Na sua visão, de que forma o Programa Residência Pedagógica pode contribuir na formação profissional dos residentes e preceptores?" foram realizadas a ambos Docentes Orientadores.

Os residentes e preceptores dos núcleos, responderam um questionário on-line, disponibilizado pelos pesquisadores através de endereço eletrônico, com tempo determinado de duas semanas para elaboração das respostas. $O$ instrumento foi composto por três questões abertas: "Porque você quis participar do PRP? Quais eram suas expectativas?"; "Quais suas expectativas futuras para com o programa? Indique motivos para justificar a manutenção ou fim do PRP:"; "O Programa Residência Pedagógica forneceu subsídios para sua formação profissional? Justifique sua resposta:".

As entrevistas foram transcritas em um documento de texto editável seguindo as orientações de Azevedo e colaboradores (2017), e os questionários online armazenados em um banco de dados. Os dados passaram por Análise de Conteúdo segundo Bardin (2016), que consiste na pré-análise, fase de operacionalização e sistematização das ideias iniciais. Na exploração do material, ocorre a codificação, decomposição ou enumeração. O tratamento dos resultados, a inferência e a interpretação foram realizadas visando resultados significativos e válidos para descrever as perspectivas iniciais e os desafios após a implementação do Programa de Residência Pedagógica na Unipampa/Uruguaiana-RS.

\section{RESULTADOS E DISCUSSÃO}

As escolas campo onde os núcleos alvo deste estudo atuam estão localizadas ao longo do perímetro urbano da cidade. As atividades desenvolvidas por estes são guiadas por duas docentes orientadoras, cada uma responsável por uma das áreas de atuação. Quanto aos residentes, estes são inseridos na escola para maior aperfeiçoamento na sua 
Vol. 3, n. 1. Jan./Abr. 2020 - ISSN 2595-4520

formação e a fim de estabelecer relações teórico-práticas necessárias à prática educativa inovadora, crítico-reflexiva e inclusiva (BRASIL, Portaria CAPES n ${ }^{\circ} 38$, 2018).

Do público total que forma os dois núcleos em estudo, houve o retorno de respostas de 04 preceptores, 25 residentes de ambos os núcleos, bem como das 02 docentes orientadoras. As respostas e discussão estão apresentadas na sequência.

\section{O PRP na visão das Docentes Orientadoras}

Quando questionadas sobre: "Qual sua percepção inicial sobre o programa de Residência pedagógica?", ambas se posicionaram quanto a implementação do PRP como uma proposta válida, apesar de sua implantação de forma verticalizada, ou seja, de cima para baixo. Segundo elas, a proposta surgiu sem diálogo com a comunidade acadêmica. Destaca-se ainda que ambas docentes concordam que, a proposta de introduzir o PRP durante a licenciatura, faz com que se efetue um complemento dentro do processo de formação e salientam a importância do preceptor (professor já formado) no acompanhamento e auxilio ao residente (acadêmico em processo de formação) no processo de imersão nas escolas.

Outro aspecto elencado foi o auxílio da bolsa ofertada pela Coordenação de Aperfeiçoamento de Pessoal de Nível Superior (CAPES), como relata a docente orientadora (DO) 1: “[...] a gente pensa na bolsa, é um estímulo para nós, principalmente para os acadêmicos, mas é um estímulo de ele olhar pro curso como algo que é bom, que vai te dar um retorno e esse retorno é um retorno tanto pessoal, pra ti ver se é realmente isso que você quer [...] estar na escola, que eu acho que é a parte mais rica $[\ldots]$ a formação acadêmico-profissional".

Corroborando com a ideia de formação acadêmico-profissional, a DO 2 expõe que: "[...] eu acredito que a Residência Pedagógica [...] ela mostrou que ela pode contribuir e que ela contribui com o processo de formação dos alunos [...] é extremamente importante, porque o aluno tem uma inserção na docência um pouco maior [...]". A docente ainda relata que as atividades realizadas conseguem fazer com que haja uma maior valorização da atividade docente e ressignificação do trabalho dos professores.

A formação de professores se dá "a partir de vivências genéricas e reais da educação" (IMBERNÓN, 2010). Nesse sentido, a compreensão das docentes orientadoras sobre o olhar dos residentes no PRP permite, muitas vezes, conforme Mota 
e colaboradores (2018), desenvolver um contato maior com a escola e a partir disto fazer uma reflexão sobre os interesses adquiridos na escola, estabelecendo uma parceria de trabalho de modo que todos os sujeitos (sejam eles residentes ou preceptores) se envolvam para um maior aperfeiçoamento profissional.

A imersão caracteriza-se como um período em que o aluno tem a oportunidade de conhecer com mais profundidade o contexto em que ocorre a docência, identificando e reconhecendo aspectos da cultura escolar; acompanhando e analisando os processos de aprendizagem pelos quais passam os alunos e levantando características da organização do trabalho pedagógico do professor formador e da escola (SILVESTRE; VALENTE, 2014). O que corrobora a ideia das docentes sobre a importância dos processos de ambientação e imersão do acadêmico no ambiente escolar.

Dando continuidade, a segunda questão da entrevista tratou sobre as expectativas futuras para o Programa Residência Pedagógica. Nesse sentido as docentes percebem diferentes nuances no processo de inserção do residente na escola e na forma como os preceptores atuam, auxiliando no processo de formação profissional destes.

\begin{abstract}
DO 1 - "O PRP tá mostrando essa expectativa de que é algo que os alunos realmente estão sentindo uma diferença de estar lá na escola, percebendo a escola, vivenciando lá no chão da escola, assumindo o papel de docente, junto com a preceptora que é isso que dá uma segurança, junto com os colegas, isso também ajuda bastante, mas claro que vai depender muito da vontade politica."

DO 2 - "O que a gente ainda pelo menos almeja, é que a gente consiga mostrar [...] o quanto o programa foi efetivo dentro dos seus objetivos nessa questão de fazer com que a relação de ensino que o aluno tem dentro do seu processo de formação na universidade e a vivência que ele teve na prática, na atuação, na docência, ela foi muito mais válida e importante do que os estágios curriculares [...]".
\end{abstract}

Fica claro na fala das docentes orientadoras que o trabalho conjunto entre residente, preceptor e docentes orientadoras favorece uma formação mais realista. A partir do compartilhamento de experiências, atividades e angústias, é possível a todos os atores do processo se desenvolver profissionalmente. Sem contar que, pela interação, é possível a todos os envolvidos vivenciar a colaboração e reflexão sobre a profissão. As docentes demonstram como expectativa principal que o programa possa ser visto com bons olhos pelos órgãos que o rege, no intuito que outros professores e acadêmicos possam ter oportunidade de formação como a qual este grupo teve. 
Vol. 3, n. 1. Jan./Abr. 2020 - ISSN 2595-4520

Quando questionadas se: "Na sua visão, de que forma o programa residência pedagógica pode contribuir na formação acadêmico-profissional dos residentes e preceptores?", ambas as docentes afirmam acreditar que a estrutura metodológica como o programa é/foi desenvolvido, auxilia na formação profissional dos residentes e preceptores. A justificativa é de que a inserção no ambiente escolar propõe a desacomodação, proporcionando a todos a consciência de estarem em processo contínuo de formação. Outro ponto também destacado é a relação do processo teoria e prática (práxis) e o vínculo que o programa proporciona entre Universidade e Escola Básica.

Para Gimenez e Chaves (2019) a presença de professores colaboradores (preceptores) das escolas parceiras pode auxiliar na validação e na construção dos saberes dos acadêmicos (residentes). $\mathrm{O}$ que demonstra o quanto é importante e o quão podem ser significativas as ações colaborativas entre as IES e as escolas de Educação Básica, especialmente no que se refere à construção da identidade docente (GIMENEZ; CHAVES, 2019).

Corroborando as respostas das docentes orientadoras, Panutti (2015) argumenta que este programa possibilita o aprimoramento da formação docente por meio da necessária articulação entre o que os alunos aprendem na universidade e o que experimentam na prática da residência. A autora considera ainda que, justamente um dos aspectos mais importantes em relação à formação docente é proporcionar ao aluno oportunidades para que desenvolva a capacidade de relacionar teoria e prática docente (PANUTTI, 2015).

Cavaco (1990) afirma que os primeiros anos da profissão, a entrada no mundo do trabalho é, simultaneamente, uma confirmação social e uma promessa de acesso à autonomia econômica e à possibilidade de construir um projeto de vida próprio, período de dúvidas e de angústias. Torna-se necessária uma ação que favoreça o encontro, os momentos de partilha, de troca de saberes, insistir na perspectiva de fortalecer que é a escola o lugar da formação dos professores, de análise partilhada das práticas, enquanto rotina sistemática de acompanhamento, de supervisão e de reflexão sobre o trabalho docente (COSTA; FONTOURA, 2015). Nesse sentido, percebeu-se pelas falas das docentes orientadoras que o Programa de Residência Pedagógica propicia interessantes vivências a todos os envolvidos.

\section{Sobre a visão dos residentes e preceptores}


Vol. 3, n. 1. Jan./Abr. 2020 - ISSN 2595-4520

Ao dar continuidade aos resultados do estudo, optou-se por mostrar a visão dos residentes e preceptores no mesmo bloco, pois acredita-se que por se tratar de sujeitos que realizam o processo de imersão de forma prática e em conjunto no ambiente escolar, a riqueza das informações obtidas se torna maior com ambos sendo relatados e discutidos conjuntamente. Com relação aos questionários online disponibilizado aos residentes e preceptores dos dois núcleos envolvidos no estudo, estes responderam a três questões abertas, que serão discutidas a seguir.

De acordo com a primeira indagação: "Porque você quis participar do PRP? Quais eram suas expectativas?", observou-se duas compreensões mais utilizadas pelos participantes: "Experiência Profissional" e "Contexto escolar". Ainda são destacados outros pontos como: a formação para atuação em sala de aula, a expectativa em vivenciar na prática as teorias aprendidas em sala de aula, a ressignificação das práticas pedagógicas, bem como a experiência em sala de aula, a atuação do residente como educador.

Os sujeitos trazem falas relativas ao que o edital propunha na época, referente ao maior tempo de imersão na escola se comparado com relação aos estágios curriculares, e ainda refletem sobre este tempo maior de imersão, e a partir desse princípio, a oportunidade de vivenciar de forma mais significativa a atuação na educação básica, evidenciado nos excertos a seguir:

\footnotetext{
R02 - "Por causa da experiência que este prometia. Esperava conhecer melhor a realidade escolar das escolas públicas."

P04 - O projeto é muito importante, todas as escolas públicas deveriam receber este programa, a vivência acadêmica com olhar inovador frente uma reflexão da prática pedagógica. Expectativas de que os conhecimentos científicos sejam vivenciados por nossos educandos.

R16 - "Esperava, com o aumento da carga horária de regência de classe, ser uma egressa do curso de Educação Física mais preparada para a docência."

R22 - "Para ter experiência durante a formação nas escolas de educação Básica, as expectativas foram de atuar na escola confrontando a teria com a prática através das experiências adquirida em conjunto com os residentes, preceptores e coordenadores do programa."
}

Estudo realizado por Santana; Barbosa (2019) na Bahia, observou que a aproximação entre universidade e escola se constitui um caminho para a orientação e acompanhamento compartilhado. A oportunidade de inserção do licenciando no contexto escolar de forma participativa, atuante e propositiva pode contribuir para a constituição do sujeito professor (SANTANA; BARBOSA, 2019). Por outro lado, a 

imersão potencializa outros modos de formação que não são possíveis na universidade. A inserção do acadêmico na escola e do professor da educação básica na universidade pode promover um maior intercâmbio da universidade com as escolas e criar possibilidades de refletir sobre questões teórico-metodológicas (SCHEID; SOARES; FLORES, 2009). Dessa forma, a distância entre escola e universidade diminui.

Em relação a: "Quais suas expectativas futuras para com o programa? Indique motivos para justificar a manutenção ou fim do PRP.", os participantes foram unânimes em indicar a necessidade de continuidade do programa. Durante a análise das respostas, as compreensões mais presentes foram: "Práticas no ambiente escolar", "Organização do programa, quanto a reformulação curricular e melhoria na organização do PRP”, "Formação acadêmico-profissional" e "Parceria entre Universidade e Escola".

Em alguns relatos, os participantes apontam alguns aspectos que podem ser melhorados com a manutenção e no decorrer das avaliações sobre o programa. Outro aspecto ressaltado é a oportunidade de um diálogo efetivo entre universidade e escola e pelo programa propiciar ao docente em formação (residentes) e os professores em atuação na escola (preceptores), subsídios para a prática no ambiente escolar. Os participantes destacaram ainda que, as políticas públicas voltadas à formação de professores têm papel essencial, não só para a formação docente em atuação, mas também para a formação e a aprendizagem do estudante (da educação básica).

\begin{abstract}
R01 - "Acredito que o programa tem extrema importância dentro da licenciatura, onde os acadêmicos aprimoram e buscam por inovações pedagógicas na prática escolar, vivenciando a rotina junto com os alunos, havendo uma troca de conhecimento, experiências e saberes ímpar para os residentes que estarão melhor preparados para a carreira docente. Sendo assim acredito que não podemos acabar com as políticas públicas de incentivo a docência. Pois apenas as aulas da universidade não nos preparam para a vivência da docência escolar."

P06 - "A expectativa é a melhor possível, pois os resultados com o programa foram muito bons, tanto para os alunos quanto para os professores."

R25 - "Eu sinceramente gostaria que o programa não se encerrasse, pois com ele, é possível que o licenciando em formação tenha a oportunidade de inserir-se ativamente no meio escolar, vivenciar a realidade dos professores regentes, elaborar planos de ensino e planos de aula, assumir a regência de classe, além de desenvolver muitas outras ações pedagógicas."
\end{abstract}

Segundo o estudo realizado por Mota e colaboradores (2018), as dificuldades encontradas são diversas no processo do ensino e aprendizagem. Nesse sentido, o programa surge como uma forma de amenizar esses bloqueios. Segundo Moretti (2007, p. 23) a "centralidade da formação na escola alia-se à concepção de formação que vê 
Vol. 3, n. 1. Jan./Abr. 2020 - ISSN 2595-4520 como essencial a articulação entre teoria e prática no processo formativo". O programa compõe-se também como uma forma de complementar os estágios das licenciaturas para os discentes (MOTA et al., 2018). A associação estabelecida e o vínculo entre formação inicial e continuada vêm numa complexidade de imersão dos processos das vivências dos residentes nas práticas pedagógicas, o que requer uma atenção, planejamento e perseverança (GIGLIO, 2010).

Faz-se necessário entender a escola como local de produção de conhecimento da profissão docente, não diminuindo a importância do conhecimento adquirido nos cursos de licenciatura, mas apostando no reconhecimento das aprendizagens que também são construídas no cotidiano da escola como fundamentais para pensar a formação de professores, pois advém das práxis (BEHREND; COUSIN; SCHMIDT, 2019). Ou seja, “teoria e prática são indissociáveis como práxis" (PIMENTA, 2012, p. 93).

A fala de alguns participantes leva a refletir sobre a reformulação do estágio curricular obrigatório, através do programa. Os estágios supervisionados consistem em uma oportunidade de o aluno aproximar-se da realidade profissional com a qual lidará, ampliando seus referenciais sobre a identidade profissional, os saberes da docência e as posturas necessárias ao exercício da profissão (PIMENTA; LIMA, 2004, p. 61). Assim, a inserção dos acadêmicos através do PRP, por se tratar de uma imersão por um período consideravelmente maior no cotidiano da escola, possibilita vivências em situações nas quais se utilizam os conhecimentos sobre o conteúdo a ser ensinado, os princípios gerais de ensino e de aprendizagem, além da didática, representando uma oportunidade para aprender a ensinar, integrando as dimensões teórica e prática (PANUTTI, 2015).

Questionados se: "O programa residência pedagógica forneceu subsídios para sua formação acadêmico-profissional? Justifique sua resposta:", todos os participantes afirmam que o programa colaborou na formação acadêmico-profissional destes. Foi possível elencar quatro temas de maior recorrência, sendo elas organizadas de acordo com as etapas e objetivos do programa: "Imersão na docência", "Processo de ambientação", "Inovação Pedagógica" e ainda são destacados os suportes realizados ao longo dos encontros com as docentes orientadoras. A seguir alguns extratos das falas mais relevantes.

$\mathrm{R}$ 07- "Forneceu sim, através dela pude conhecer bem a realidade escolar, pois se tem mais tempo dentro de uma escola do que o próprio estágio que é 
Vol. 3, n. 1. Jan./Abr. 2020 - ISSN 2595-4520 pouco tempo, enfim a residência Pedagógica me forneceu uma gama de conhecimentos que levarei pra vida profissional fora da universidade.";

P 21 - "São experiências formidáveis e impagáveis para a minha formação. Centenas de pessoas envolvidas na comunidade escolar que colaboram com um pequeno pedaço do universo de um professor. Sem dúvida obtive um novo olhar sobre a minha prática ensinando que levarei para o resto da minha vida profissional.";

P 27 - "Sim. A troca de experiência e a aproximação com a os futuros profissionais e muito válida, todos tem a ganhar com essa troca."

Percebe-se a partir da análise das respostas e também com os extratos mencionados anteriormente, que apesar de ser um programa recente e apresentar algumas falhas referentes a organização na visão de alguns participantes atuantes, o PRP está respondendo aos seus principais objetivos. Dentre eles, destaca-se um recorte do próprio edital, que explica a funcionalidade do mesmo: "consiste na imersão planejada e sistemática do aluno de licenciatura em ambiente escolar visando à vivência e experimentação de situações concretas do cotidiano escolar e da sala de aula que depois servirão de objeto de reflexão sobre a articulação entre teoria e prática" (BRASIL, Edital CAPES, 06/2018).

A presença dos preceptores na orientação dos residentes é de suma importância, pois se realizam à mediação de conhecimentos, experiências, reflexão, ação, teorização e formalização, no sentido de vincular o conhecimento teórico a prática. Certamente, o reconhecimento da realidade da educação e da escola pública brasileira hoje requer de todos os formadores uma atenção com ideias inovadoras para tentar superar certas condições que desvalorizam o ensino (MOTA et al., 2018).

A proposta de maior articulação entre as instituições ainda é um propósito a ser alcançada, ou melhorada após esse primeiro período de PRP na instituição onde se deu a pesquisa, pois muitos são os desafios para implementação de ações colaborativas entre escola e universidade. Para o desenvolvimento de ações conjuntas e com propósitos comuns, Diniz-Pereira (2008) aponta a necessidade de romper com modelos de racionalidade técnica de formação, superar a visão aplicacionista e o discurso prescritivo na formação de professores, para assim poder entender a triangulação entre professor regente, professor orientador e futuros professores neste processo (BEHREND; COUSIN; SCHMIDT, 2019). Nesse sentido, o PRP é um passo nessa direção.

Quanto aos espaços para a prática na formação inicial de professores e gestores escolares, estes se constituem como um âmbito repleto de possibilidades e de elevado 
Vol. 3, n. 1. Jan./Abr. 2020 - ISSN 2595-4520 potencial para a inovação na formação de professores. Esse novo status conferido aos estágios e às atividades práticas no interior dos currículos das licenciaturas, apesar das diretrizes legais (Pareceres CNE, 2001, 2002, 2006), enfrenta fragilidades de várias ordens. Entre elas "a permanência de uma cultura desenvolvida ao longo do tempo na universidade, que tende a desvalorizar a formação prática e os cenários de aprendizagem profissional". (GIGLIO; LUGLI, 2013, p. 63). Por outro lado, como mencionado por preceptores, residentes e docentes orientadoras, é importante a manutenção do programa para uma real reformulação curricular e assim uma significativa imersão do acadêmico na escola, possibilitando uma relação efetiva entre a teoria estudada e a prática vivenciada no ambiente escolar.

\section{CONSIDERAÇÕES FINAIS}

Observou-se, a partir das análises realizadas que, duas foram as considerações mais impactantes. A primeira é quanto a bolsa ou auxílio ofertado pela CAPES, que segundo o relato das docentes orientadoras seria uma das mais atrativas intenções pelas quais os acadêmicos e professores da rede básica teriam aceito se inscrever no edital de seleção para participar do programa. Tal argumento explicitamente não se confirmou, pois, ao indagar-se as motivações que levaram tanto residentes quanto preceptores a participar do programa, observou-se a menção à Formação Acadêmico-Profissional. Percebeu-se que o programa direta ou indiretamente, promove uma interação bastante forte entre universidade e escola e vice-versa, pois o que surgiu para a discussão deste é a relação que o acadêmico percebe quando adentra o universo escolar, ao longo da discussão sendo essa relação caracterizada como prática docente, bem como a relação do professor da rede pública que se insere na produção cientifica de materiais oriundos das diversas atividades realizadas com os acadêmicos e com as docentes da IES.

Ao finalizar, salienta-se a necessidade de estudos voltados a avaliação do processo de implementação do Programa de Residência Pedagógica, o impacto deste na formação de professores, os efeitos da imersão do programa na escola, bem como na relação entre escola de educação básica e instituição de ensino superior. Mesmo que estes sejam realizados de forma crítica, podem trazer diversos elementos que sirvam para a manutenção e aperfeiçoamento do programa e não apenas como forma de 
Vol. 3, n. 1. Jan./Abr. 2020 - ISSN 2595-4520

identificar problemáticas sem que sejam apontadas soluções ou estratégias para melhor atender aos objetivos do programa.

\section{REFERÊNCIAS}

AZEVEDO, Vanessa et al. Transcrever entrevistas: questões conceptuais, orientações práticas e desafios. Rev. Enf. Ref., Coimbra, v. ser IV, n. 14, p. 159-168, set. 2017. Disponível em <http://www.scielo.mec.pt/scielo.php?script=sci_arttext\&pid=S087402832017000300016\&lng=pt\&nrm=iso>. Acesso em 20 fev. 2020.

http://dx.doi.org/10.12707/RIV17018.

BARDIN, Lawrence. Análise de conteúdo. São Paulo: Edições 70, 2016.

BEHREND, Danielle Monteiro; COUSIN, Cláudia da Silva; SCHMIDT, Elisabeth Brandão. A relação interinstitucional entre escola e universidade no contexto dos estágios curriculares supervisionados. Laplage em Revista, [S.1.], v. 5, n. 1, p.85-94, fev. 2019.

BRASIL. Lei n. 9.394, de 20 de dezembro de 1996. Estabelece as diretrizes e bases da educação nacional. Diário Oficial [da] República Federativa do Brasil. Brasília, DF, 23/12/1996, p.27.833.

BRASIL. Ministério da Educação. Parecer CNE/CP n⿳0 009/2001. Institui Diretrizes Curriculares para a Formação de Professores da Educação Básica, em nível superior, curso de licenciatura, de graduação plena.

BRASIL. Ministério da Educação. Resolução CNE/CP n. 1/2006. Institui Diretrizes Curriculares para o Curso de Graduação em Pedagogia, licenciatura.

BRASIL. Ministério da Educação. Resolução CNE/CP 1, de 18 de fevereiro de 2002. Diário Oficial da União, Brasília, 4 de março de 2002. Seção 1, p. 8.

BRASIL. Ministério da Educação. Portaria CAPES No 38, de 28 de fevereiro de 2018. Institui o Programa de Residência Pedagógica. Diário Oficial da União no 41, de 01 de março de 2018 - Seção 1- pág. 28.

BRASIL. Edital CAPES 06/2018. Dispõe sobre a Residência Pedagógica. Disponível em https://www.capes.gov.br/images/stories/download/editais/01032018-Edital-6-2018residencia-pedagogica.pdf. Acesso em: 20 de outubro de 2019.

CAVACO, Maria Helena. Retrato do professor enquanto jovem. Revista Crítica de Ciências Sociais, Fev/1990, p. 121-139. Disponível em:

https://www.ces.uc.pt/publicacoes/rccs/029/MHCavaco pp.121-139.pdf. Acesso em: 24 de nov. 2019.

COSTA, Luciana Laureano; FONTOURA, Helena Amaral da. Residência pedagógica: criando caminhos para o desenvolvimento profissional docente. Revista 
Vol. 3, n. 1. Jan./Abr. 2020 - ISSN 2595-4520

@ mbienteeducação, Universidade cidade de São Paulo, Vol. 09, nº 02 jul/dez, 2015 , 161-177.

DINIZ-PEREIRA, Júlio Emílio. A formação acadêmico-profissional: Compartilhando responsabilidades entre as universidades e escolas. Trajetórias e processos de ensinar e aprender: didática e formação de professores. In: XIV ENDIPE, 2008, Pontifícia Universidade Católica do Rio Grande do Sul (PUCRS), Porto Alegre. Anais... Porto Alegre, 2008.

DINIZ-PEREIRA, Júlio Emílio. A prática como componente curricular na formação de professores. Educação, Santa Maria, v. 36, n. 2, p. 203-218, maio/ago. 2011.

GIGLIO, Célia Maria Benedicto. Residência Pedagógica como diálogo permanente entre a formação inicial e continuada de professores. In: DALBEN, A. et al. (Org.). Convergências e tensões no campo da formação e do trabalho docente. $1^{\mathrm{a}}$ ed. Belo Horizonte: Autêntica, 2010, v. 1, p. 375-392.

GIGLIO, Célia Maria Benedicto; LUGLI, Rosario Silvana Genta. Diálogos pertinentes na formação inicial e continuada de professores e gestores escolares. A concepção do programa de residência pedagógica na UNIFESP. Cadernos de Educação, Pelotas, 46, p. 62-82, 2013.

GIL, Antonio Carlos. Como elaborar projetos de pesquisa. $5^{a}$ ed. São Paulo: Atlas, 2010.

GIMENEZ, Alana Pereira; CHAVES, Taniamara Vizzotto. O Pibid como espaço de construção de saberes docentes em um curso de Licenciatura em Física. Revista Insignare Scientia - RIS, v. 2, n. 4, p. 219-237, 19 dez. 2019.

IMBERNÓN, Francisco. Formação continuada de professores. Porto Alegre: Artmed, 2010.

MELLO, Elena Maria Billig; FREITAS, Diana Paula Salomão. Formação acadêmicoprofissional de professores(as). Revista Brasileira de Pesquisa sobre Formação de Professores. Belo Horizonte - MG, v. 11, n. 20, jan./abr. 2019.

MINAYO, Maria Cecília de Souza. (org) Pesquisa social: teoria, método e criatividade. 20 ed. Petrópolis: Vozes, 2002.

MORETTI, Vanessa Dias. Professores de Matemática em atividade de ensino: uma perspectiva histórico-cultural para a formação docente. Tese (Doutorado em Educação) - Faculdade de Educação, Universidade de São Paulo, 2007.

MOTA, Aislânia da Silva et al. Residência pedagógica: uma contribuição para a formação inicial de professores. Anais: VII ENALIC - Encontro Nacional das Licenciaturas. Fortaleza-CE, p. 01-09. 2018. Disponível em: http://editorarealize.com.br/revistas/enalic/trabalhos/443-55106-29112018-111245.pdf. Acesso em: 10 de novembro de 2019. 
Vol. 3, n. 1. Jan./Abr. 2020 - ISSN 2595-4520

NÓVOA, Antônio Sampaio da. Firmar a posição como Professor, Afirmar a Profissão

Docente. Cadernos de Pesquisa, v.47, n.166, p.1106-1133, out./dez, 2017.

NÓVOA, Antônio Sampaio da. Formação de professores e profissão docente. In. NÓVOA, A. S. (Coord). Os professores e a sua formação. 2. Ed. Lisboa: Dom Quixote, 1995. p. 15-33.

PANUTTI, Maísa Pereira. A relação teoria e prática na Residência Pedagógica. Anais: XII Congresso Nacional de Educação. Curitiba-PR, 2015, p. 8433-8440. Disponível em: https://educere.bruc.com.br/arquivo/pdf2015/15994_8118.pdf.

PIMENTA, Selma Garrido; LIMA, Maria Socorro Lucena. Estágio e Docência. São Paulo: Cortez, 2004.

PIMENTA, Selma Garrido. O estágio na formação de professores: Unidade Teoria e Prática? 11 ${ }^{\mathrm{a}}$ ed. São Paulo: Cortez, 2012.

SANTANA, Flávia Cristina de Macêdo; BARBOSA, Jonei Cerqueira. A relação universidade/escola e o Programa Residência Pedagógica/subprojeto de matemática: estratégias de poder e modos de subjetivação. Revista Sergipana de Matemática e Educação Matemática, v. 4, n. 2, p. 1-24, 2019.

SCHEID, Neusa Maria John; SOARES, Briseidy Marchesan; FLORES, Maria Lorete Thomas. Universidade e Escola Básica: uma importante parceria para o aprimoramento da educação científica. $\boldsymbol{R}$. B. E. C. T., v. 2, n. 2, mai./ago. 2009.

SILVESTRE, Magali Aparecida; VALENTE, Wagner Rodrigues. Professores em Residência Pedagógica: Estágio para ensinar matemática. Petrópolis: Vozes, 2014. 